\title{
Synthesis of coumarins by ring-closing metathesis*
}

\author{
Arnab K. Chatterjee, F. Dean Toste, Steven D. Goldberg, and \\ Robert H. Grubbs ${ }^{\ddagger}$
}

\begin{abstract}
Arnold and Mabel Beckman Laboratories for Chemical Synthesis, Division of Chemistry and Chemical Engineering, California Institute of Technology, Pasadena, CA 91125, USA
\end{abstract}

\begin{abstract}
Investigations into olefin ring-closing metathesis (RCM) have led to a general method for the synthesis of coumarins. Catalysts with higher activity, such as the second-generation ruthenium catalyst, promote the intramolecular reaction between two-electron deficient olefins. This method allows for convenient access to a variety of coumarins substituted at both the 3- and 4-positions, as well as a tetrasubstituted example.
\end{abstract}

Olefin metathesis is a convenient method to construct alkene-containing compounds for use in a variety of areas of organic chemistry. For example, olefin metathesis has been widely used in polymer synthesis by ring-opening metathesis polymerizations (ROMP) [1] and step-growth polymerizations, such as acyclic diene metathesis polymerization (ADMET) [2]. Recently, the application of olefin metathesis to small molecule synthesis has emerged as a powerful synthetic method. For example, ring-opening metathesis (ROM) of strained olefins has provided new routes in the synthesis for a variety of natural products [3]. More importantly, the application of ring-closing metathesis (RCM) in total synthesis has received a great deal of attention, giving synthetic chemists the confidence to subject highly valuable materials to RCM reactions [4].

Work in our group has been focused on applying RCM to the synthesis of novel and important highly functionalized products. Many of these discoveries have been due to the availability of catalysts with varied activities, such as $\mathbf{1}$ [5], 2 [6], and 3 [7] (Fig. 1). In particular, the development of ruthenium-imidazoylidene catalyst $\mathbf{1}$, has greatly expanded the substrate range in olefin metathesis reactions. The application of catalyst $\mathbf{1}$ in RCM has been demonstrated with several important new results. For example, in macrocyclic RCM where both cis and trans products are formed, greater trans stereoselectivity was observed using catalyst 1 rather than the parent bis-phosphine catalyst 2 [8]. Catalyst 1 provides a synthetically useful 11.5:1 E/Z mixture of olefin isomers in a 14-member lactone, which

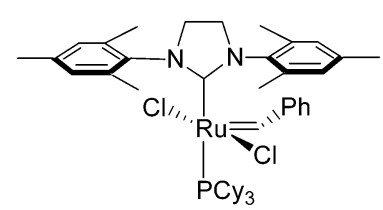

1

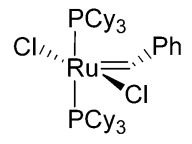

2

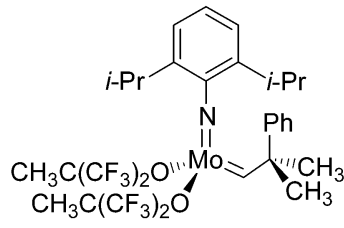

3

Fig. 1 Commonly used olefin metathesis catalysts.

\footnotetext{
*Plenary lecture presented at the $\mathrm{XX}^{\text {th }}$ International Conference on Organometallic Chemistry (ICOMC), Corfu, Greece, 7-12 July 2002. Other presentations are published in this issue, pp. 421-494.

¥Corresponding author
} 
translates to $250 \%$ enrichment of the trans olefin product as compared to catalyst $\mathbf{2}$, which provides the product in a 4.5:1 E/Z ratio. This is believed to occur by olefin isomerization to the more thermodynamically favorable trans isomer, which occurs to a greater extent with catalyst $\mathbf{1}$. In addition, new RCM reaction manifolds have been discovered using catalyst 1. Our group [9] and others [10], have reported the RCM of acrylate esters to form $\alpha, \beta$-unsaturated esters and ketones using catalyst $\mathbf{1}$ and related derivatives. This unique activity has been expanded to prepare large macrocycles by a ring expansion reaction (Scheme 1). These reactions proceed via an initial ring-opening of the cyclic olefin, then a cross-metathesis $(\mathrm{CM})$ with one $\alpha, \beta$-unsaturated carbonyl olefin, and finally a macrocyclic RCM to generate 18-26-member macrocycles. In general, these reactions proceed in good-to-moderate yields, providing a rapid method to generate macrocyclic carbon structures with trans olefin selectivity.
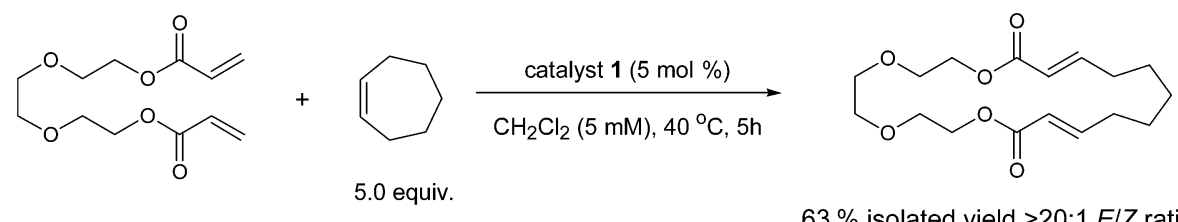

$63 \%$ isolated yield $>20: 1 E / Z$ ratio

Scheme 1 Ring-expansion by sequential ROM/CM/macrocyclic RCM.

While catalyst $\mathbf{1}$ has been successful in improving substrate scope and stereoselectivity in RCM, we have seen a more dramatic effect within the context of olefin CM. In general, CM has been a less utilized method in organic synthesis due to low product selectivity and poor olefin stereoselectivity. A wide variety of olefins that do not participate in CM using catalysts $\mathbf{2}$ and $\mathbf{3}$ are now viable substrates for highly selective CM reactions that proceed with excellent trans stereoselectivity. Such olefins include $\alpha, \beta$-unsaturated carbonyl containing olefins, vinylphosphonate, and vinyl sulfones [11]. In addition, selective CM reactions have been performed between electron-deficient groups in a Heck-type coupling of acrylates and styrenes (Scheme 2) [12]. This was an important discovery because it had been previously proposed that two $\pi$-substituted olefins could not participate in selective CM reactions, due to similar electronic properties [13]. Interestingly, there has been no analogous report in the RCM literature that describes a ring-closure between two electron-deficient olefins. This provides a unique opportunity to contribute to the more mature area of RCM, using lessons learned in CM.

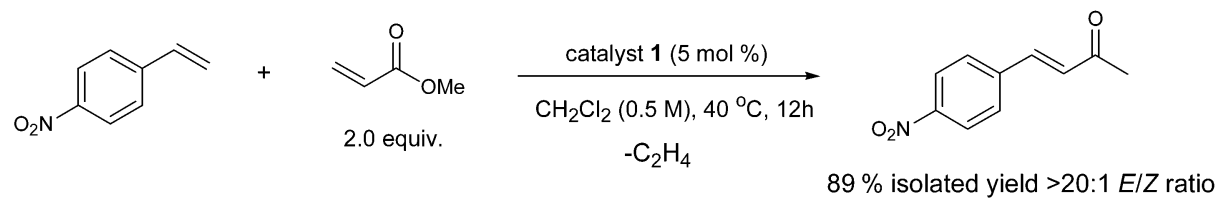

Scheme 2 Olefin CM between two electron-deficient olefins.

Coumarins represent an important class of compounds due to their importance in biological systems [14]. There have been a wide variety of noncatalytic methods to synthesize coumarins, such as the Pechmann condensation of $\beta$-ketoesters [15]. However, this method generally requires strong acids and high reaction temperatures. In addition, there have been several metal-catalyzed approaches to coumarins, including a palladium-catalyzed reaction between phenols and alkynoates [16]. While offering a significantly milder room temperature approach to synthesize these compounds, substitution at the 3-position is not possible due to use of alkyne precursors. There is an example of the synthesis of 3-substituted coumarins by a rhodium-catalyzed carbonylation of alkynyl phenols [17]. While this procedure provides the desired product, it is a minor component with the corresponding 3-benzofuranone. In addi- 
tion, nickel-catalyzed cross-coupling of coumarin 4-phosphonates been developed as an alternative method to prepare a variety of 4-substituted coumarins [18].

Therefore, with our previous results in CM between acrylates and styrenes, we were interested in investigating the RCM of similar compounds as a route to substituted coumarins both at the 3-and/or 4-positions (Scheme 3). The RCM substrates could be easily prepared by acylation of the corresponding phenol. The required styrenyl phenols may be accessible from a suitable ketone starting material, such as acetophenone. Another advantage of this route is that a variety of acrolyl chlorides can be used to provide substitution at the 3-position, which is not possible using alternative methods. Herein we report the RCM of styrenyl acrylates that provide the coumarin compounds in moderate-to-excellent yield under mild conditions.<smiles>[R]c1c([R])c2ccccc2oc1=O</smiles><smiles>[R]C(=C)C(=O)Oc1ccccc1C([R])=C</smiles><smiles>[R]C(=C)C(=O)Cl</smiles><smiles>[R]C(=C)c1ccccc1O</smiles><smiles>C=C</smiles><smiles>[R]C(=O)c1ccccc1O</smiles>

Scheme 3 Retrosynthesis of tetrasubstituted coumarins by RCM.

We began our synthesis with the commercially available 2-propenylphenol (4) (Scheme 4). The acylation step proceeds smoothly with acrolyl chloride to provide $\mathbf{5}$ in $72 \%$ isolated yield. The RCM reactivity of $\mathbf{5}$ was then explored using catalysts $\mathbf{1}$ and $\mathbf{2}$. We were gratified to find that catalyst $\mathbf{1}$ ( $3 \mathrm{~mol} \%$ ) provided the coumarin (6) in excellent yield (89\%), whereas catalyst $2(10 \mathrm{~mol} \%)$ was not able to affect detectable ring-closing. This further illustrated the electron-deficient nature of these substrates, since related chromenes are readily prepared by RCM with catalyst 2 [19]. To investigate the synthesis of more substituted coumarins by RCM, ring-closing precursor compound $\mathbf{8}$ was efficiently prepared from commercially available 2-hydroxyacetophenone (7) in two steps (Scheme 5). To afford the ring-closed product, a higher catalyst loading was required (10 mol \%), and provided 3,4-dimethylcoumarin (9) in moderate yields.
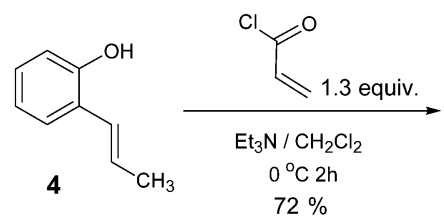<smiles>C=CC(=O)Oc1ccccc1/C=C/C</smiles>

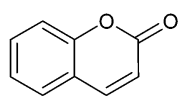

6

Catalyst $1(3 \mathrm{~mol} \%)=89 \%$ isolated yield Catalyst $2(10 \mathrm{~mol} \%)=$ No Reaction

Scheme 4 Synthesis of a coumarin by RCM.<smiles>CC(=O)c1ccccc1O</smiles>

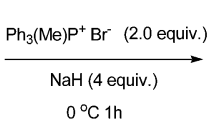

$90 \%$ isolated yield

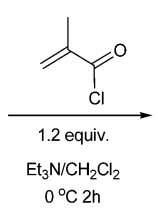

$67 \%$ isolated yield

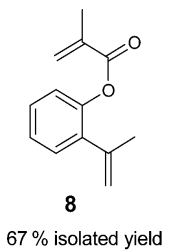

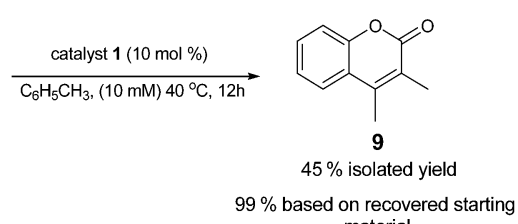

Scheme 5 Synthesis of 3,4-dimethylcoumarin from 2-hydroxyacetophenone.

In addition, the RCM reaction is very clean, allowing for full recovery of unreacted starting material. This reaction is one of the few examples of the formation of a tetrasubstituted olefin by RCM, and is particularly remarkable when one considers the electron-deficient nature of the olefins involved. We 
Table 1 Summary of substituted coumarins by RCM.

Entry $\quad$ Catalyst 1 Temp. $\left({ }^{\circ} \mathrm{C}\right)$

also wished to investigate trisubstituted olefins, and the results are summarized in Table 1. RCM provides a unique route to 3-methylcoumarin (10) from a simple acylation of $\mathbf{4}$ with methacrolyl chloride, followed by RCM with catalyst $\mathbf{1}$ in an $88 \%$ isolated yield.

In summary, a RCM route to coumarins is described using the highly active ruthenium-based catalyst $\mathbf{1}$. The unique reactivity of this catalyst allows for the synthesis of both trisubstituted and tetrasubstituted coumarins. In addition, the fact that catalyst $\mathbf{1}$ can perform RCM with two electron-deficient olefins is unique. These reactions further demonstrate the utility of olefin metathesis for the synthesis of biologically important molecules.

\section{REFERENCES}

1. For a recent review: U. Frenzel and O. Nuyken. J. Polym Sci. Part A 40, 2895 (2002); (b) There is also an example of a polynorbornene with pendant coumarins made by ROMP, see: M. A. Tlenkopatchev, S. Fomine, L. Fomina, R. Gavino, T. Ogawa. Polymer J. 29, 622 (1997).

2. For some recent examples, see: A. C. Church, J. H. Pawlow, K. B. Wagener. Macromolecules 35, 5746 (2002); (b) H. Tamura and H. A. Nakayama J. Macromol. Sci. Pure. 39, 745 (2002).

3. T. O. Schrader and M. L. Snapper J. Am. Chem. Soc. 124, 10776 (2002).

4. A. Furstner. Angew. Chem. 112, 3013 (2000), Angew. Chem., Int. Ed. 39, 3140 (2000); (b) T. M. Trnka and R. H. Grubbs. Acc. Chem. Res. 34, 18 (2001); (c) S. Kotha and N. Sreenivasachary. Ind. J. Chem. B 40, 763 (2001).

5. (a) M. Scholl, S. Ding, C. W. Lee, R. H. Grubbs. Org. Lett. 1, 953 (1999); (b) M. S. Sanford, J. A. Love, R. H. Grubbs. J. Am. Chem. Soc. 123, 6543 (2001).

6. (a) P. Schwab, M. B. France, J. W. Ziller, R. H. Grubbs. Angew. Chem. 107, 2179 (1995); Angew. Chem., Int. Ed. Engl. 34, 2039 (1995); (b) P. Schwab, R. H. Grubbs, J. W. Ziller J. Am. Chem. Soc. 118, 100 (1996); (c) T. R. Belderrain and R. H. Grubbs. Organometallics 16, 4001 (1997).

7. (a) R. R. Schrock, J. S. Murdzek, G. C. Bazan, J. Robbins, M. Dimare, M. O'Regan. J. Am. Chem. Soc. 112, 3875 (1990); (b) G. C. Bazan, E. Khosravi, R. R. Schrock, W. J. Feast, V. C. Gibson, M. B. O'Regan, J. K. Thomas, W. M. Davis. J. Am. Chem. Soc. 112, 8378 (1990); (c) G. C. Bazan, J. H. Oskam, H. N. Cho, L. Y. Park, R. R. Schrock. J. Am. Chem. Soc. 113, 6899 (1991). 
8. C. W. Lee and R. H. Grubbs. Org. Lett. 2, 2145 (2000).

9. (a) A. K. Chatterjee, J. P. Morgan, M. Scholl, R. H. Grubbs. J. Am. Chem. Soc. 122, 3783 (2000);

(b) C. W. Lee and R. H. Grubbs. J. Org. Chem. 66, 7155 (2001).

10. (a) A. Fürstner, O. R. Thiel, L. Ackermann, H.-J. Schanz, S. P. Nolan. J. Org. Chem. 65, 2204 (2000); (b) A. Fürstner, O. R. Thiel, N. Kindler, B. Bartkowska. J. Org. Chem. 65, 7990 (2000); (c) A. Fürstner, O. R. Thiel, L. Ackermann. Org. Lett. 3, 449 (2001).

11. (a) A. K. Chatterjee, J. P. Morgan, M. Scholl, R. H. Grubbs. J. Am. Chem. Soc. 122, 3783 (2000); (b) T.-L. Choi, A. K. Chatterjee, R. H. Grubbs. Angew. Chem., Int. Ed. 39, 1277 (2000); (c) A. K. Chatterjee, T.-L. Choi, R. H. Grubbs. Synlett 1034 (2001); (d) K. Grela and M. Bieniek. Tetrahedron Lett. 42, 6425 (2001); (e) T.-L. Choi, C. W. Lee, A. K. Chatterjee, R. H. Grubbs. J. Am. Chem. Soc. 123, 10417 (2001); (f) A. K. Chatterjee and R. H. Grubbs. Angew. Chem., Int. Ed. 41, 3171 (2002).

12. A. K. Chatterjee, F. D. Toste, T.-L. Choi, R. H. Grubbs. Adv. Synth. Catal. 344, 634 (2002).

13. W. E. Crowe and D. R. Goldberg. J. Am. Chem. Soc. 117, 5162 (1995).

14. (a) B. Naser-Hijazi, B. Stolze, K. S. Zanker. Second Proceedings of the International Society of Coumarin Investigators, Springer, Berlin (1994); (b) F. Cottiglia, G. Loy, D. Garau, C. Floris, M. Casu, R. Pompei, L. Bonsignore. Phytomedicine 8, 302 (2001).

15. (a) S. Sethna and R. Phadke. Org. React. 7, 1 (1953); (b) C. E. Cook, R. C. Corley, M. E. Wall. J. Org. Chem. 30, 4114 (1965).

16. Initially reported by: (a) B. M. Trost and F. D. Toste. J. Am. Chem. Soc. 118, 6305 (1996); (b) Subsequent report by: C. Jia, D. Piao, J. Oyamada, W. Lu, T. Kitamura, Y. Fujiwara. Science 287, 1992 (2000).

17. E. Yoneda, T. Sugioka, K. Hirao, S.-W. Zhang, S. Takahashi. J. Chem. Soc., Perkin Trans. 1477 (1998).

18. J. Wu and Z. Yang. J. Org. Chem. 66, 7875 (2001).

19. S. Chang and R. H. Grubbs. J. Org. Chem. 63, 864 (1998). 